\title{
Lamina propria eosinophils and mast cells in ulcerative colitis: comparison between Asians and Caucasians
}

\author{
G F A Benfield, R Bryan, J Crocker
}

\begin{abstract}
To investigate the theory of hypersensitivity in the colonic mucosa of Asian patients with ulcerative colitis the rectal biopsy specimens of Asian and Caucasian patients presenting with colitis were selectively stained for both eosinophils and mast cells. Comparisons between ethnic groups were made as well as the correlation to the blood eosinophil count and two variables of active ulcerative colitis-the blood leucocyte count and serum orosomucoid concentration. No correlation was found in either group between circulating and tissue eosinophils and no ethnic difference was identified in the lamina propria differential cell densities. The leucocyte count and serum orosomucoid concentrations, however, were significantly higher in the Caucasians. In the Asian group a strong negative association was found between the lamina propria eosinophil density and serum orosomucoids; in the Caucasian group there was a positive association between all blood variables.
\end{abstract}

It is concluded that different mechanisms occur in the two ethnic groups and in Asians these might not be reflected by the more orthodox indices of colonic inflammation.

An ethnic difference in the prevalence of eosinophils in untreated ulcerative colitis has been shown ${ }^{1}$ with 19 of a group of $44(43 \%)$ Asian immigrants having a raised eosinophil count but only three subjects $(7 \%)$ in a comparable Caucasian group. In the absence of parasitic disorders or other eosinophil related illnesses to explain this phenomenon the possibility is that an eosinophilia in such patients may reflect a differing pathogenesis in ulcerative colitis or a peculiar racial response to some aspect of the colitic process.

The presence of eosinophilia implies that some "allergic" (hypersensitivity) immune mechanism may underly a disorder and this could conceivably be present in those groups with ulcerative colitis who have such a cellular response. Alternatively, eosinophilia may reflect an IgE mediated response to a secondary event consequent to an inflamed bowel mucosa. Thus eosinophilia may well reflect similar cellular events occurring in colonic tissue. It is well known that eosinophils occur in increased numbers in both the rectal mucosa ${ }^{23}$ and in the inflammatory exudate, ${ }^{4}$ although there is a poor correlation between the presence of increased tissue and numbers of circulating eosinophils. The demonstration of large numbers of IgE producing cells in patients with proctitis ${ }^{5}$ and more extensive ulcerative colitis ${ }^{6}$ led the authors to suggest that an allergic mechanism may be important. Binder and Hvidberg measured the histamine content of defatted rectal biopsy specimens and showed that mucosal histamine was significantly increased in those patients with pronounced eosinophilia in the inflammatory exudate. ${ }^{7}$ They suggested an allergic reaction in the mucosa as the reason, there being no correlation with severity or duration of disease.

The mast cell, also intimately involved in allergic responses at the mucosal level, has also been shown in increased numbers in ulcerative colitis. ${ }^{89}$ The mast cell releases inflammatory mediators including histamine, prostaglandins, leukotrienes and ECF-A following IgEmediated degranulation as part of a hypersensitivity response to foreign antigens. Thus eosinophils and mast cells are usually found together in increased numbers at the sites of allergic reactions.

The finding of a circulating eosinophilia in Asian immigrants with ulcerative colitis suggests that some allergic mechanism may be responsible. If so, an increase in mucosal eosinophils and mast cells might be expected in the inflamed portion of the large bowel. This study was undertaken to investigate these cellular associations in colorectal biopsy specimens of Asian immigrants and indigenous Caucasians with ulcerative colitis. The aim was to discover whether an allergic cell response was present in Asians which would explain the eosinophilia.

\section{Patients and methods}

Biopsy specimens in paraffin wax blocks containing sufficient material and previously stained sections (haematoxylin and eosin) from 36 Asians and 38 Caucasians diagnosed as having ulcerative colitis were retrieved for the purpose of this study. All specimens had been fixed in formol-saline. The clinical diagnosis of ulcerative colitis was based on an appropriate history and clinical examination, sigmoidoscopic appearances, and subsequent barium examination or fibre optic colonoscopy of the large bowel. In all patients parasitic infestation had been rigorously sought and excluded. The subsequent clinical behaviour or further biopsies and colonoscopic examination confirmed
Correspondence to: Dr J Crocker, Department of Hospital, Bordesley Green East, Birmingham B9 5ST Accepted for publication 30 August 1989 
chronic ulcerative colitis and excluded acute self-limiting (infectious type) colitis.

The two groups of patients were matched for age, sex, and extent of colonic inflammation. The biopsy material used had been obtained on first presentation to hospital and none of the patients had been receiving specific treatment such as sulphasalazine and corticosteroids, either topically or systemically.

A control group was formed consisting of 12 patients who had undergone a sigmoidoscopic examination as part of their investigation but in whom no enterocolic pathology was established. The diagnoses or disabilities in this group were: diverticular disease $(n=2)$, constipation $(n=2)$, anaemia-duodenal ulcer $(n=1)$, abdominal pain-no cause $(n=1)$, cardiac failure $(n=1)$, rapid intestinal transit $(n=1)$, recurrence of carcinoma of the colon $(n=1)$, suspected malabsorption $(n=1)$, cardiac amyloid $(n=1)$, adhesions $(n=1)$.

In all three groups $3 \mu \mathrm{m}$ sections were cut from the original blocks and processed in an identical manner. For each subject one section was stained for eosinophils with Vital New Red (VNR) according to the method of $\mathrm{Li}, \mathrm{Yam}$, and Crosby ${ }^{10}$ and a second section was stained for mast cells using Astra Blue as described by Blaies and Williams. ${ }^{11}$

Sections were counted blind by one of us (GFAB), all slides being identified only by the original laboratory registration number, the patient identification being undertaken only after completion of cell counting. All stained and mounted sections were examined and counted using the same standard Zeiss twineyepiece microscope. A counting graticule (Graticules Ltd, Tonbridge, Kent) was incorporated into the $\mathrm{x} 10$ eyepiecce projecting a counting grid of $0.1 \times 0.1 \mathrm{~mm}\left(0.01 \mathrm{~mm}^{2}\right)$. A x100 oil immersion objective lens was used, thus resulting in a total magnification of $\times 1000$.

The section to be counted was evaluated overall to assess any variations in cell density and the presence of any collections of lymphocytes (in which eosinophils and mast cells are absent). If the density of the inflammatory cell infiltrate was patchy then both high and low density areas were counted to improve overall accuracy. The grid was sited over fields free of intrusion by epithelial surfaces, glands, crypts or blood vessels. With the aforementioned provisos counts were undertaken from five randomly chosen areas, the results averaged for each patient, and converted to cells $/ \mathrm{mm}^{2}$. The VNR stain plus counterstain allowed both a total lamina propria cell density $\left(x 10^{3} / \mathrm{mm}^{2}\right)$ and an eosinophil density (cells $/ \mathrm{mm}^{2}$ ) to be obtained. A mast cell density was similarly obtained from the section stained with Astra Blue.

From the records of the 36 Asians and 38 Caucasians, details were obtained of the blood leucocyte and eosinophil count and the serum orosomucoid concentration measured at presentation. The latter index, in particular, correlates well with inflammatory activity. ${ }^{12} 13$

Only serum orosomucoid values were normally distributed and intergroup analysis was by Student's $t$ test (two tailed). Blood and
Table 1 Characteristics of Asians and Caucasians presenting with active untreated ulcerative colitis

\begin{tabular}{llll}
\hline & Asians & Caucasians & p Value \\
\hline Male:Female & $24: 12$ & $26: 12$ & \\
Age (mean (SD) in years & $30 \cdot 7(11 \cdot 5)$ & $32.9(13 \cdot 7)$ & 0.24 \\
Extent of disease: & & & \\
$\quad$ Proctitis & 11 & 8 & \\
Left sided colitis & 5 & $9 \chi^{2}=1.59$ & 0.45 \\
Total colitis & 20 & 21 & \\
\hline
\end{tabular}

tissue cell data in the two groups with ulcerative colitis were compared using Wilcoxon's rank sum test and cell analysis of three groups was analysed with one way analysis of variance. The correlation between two variables was assesssed using Spearman's rank order correlation coefficient. Derived $p$ values of $<0.05$ were regarded as significant.

The reproducibility of cell density values obtained was assessed by repeating counts blind by the same person on 12 randomly chosen patients. The two sets of densities obtained were compared using linear regression analysis.

\section{Results}

The patient characteristics of both groups with ulcerative colitis are summarised in table 1 . Although Asians had relatively more proctitis than left sided colitis, this difference did not reach significance.

The distribution of mean total lamina propria cell densities for patients in all three groups is illustrated in fig 1 ; the corresponding mean lamina propria eosinophil and mast cell densities are shown in fig 2. There was no difference between the two groups with ulcerative colitis in respect of tissue cell densities, although all were significantly higher than those in the control group (table 2). The mean serum orosomucoid and leucocyte count, however, were higher in Caucasians while the blood eosinophil count was higher in the Asian group.

The occurrence of increased lamina propria cell densities in ulcerative colitis if control group densities are taken as the normal range, is

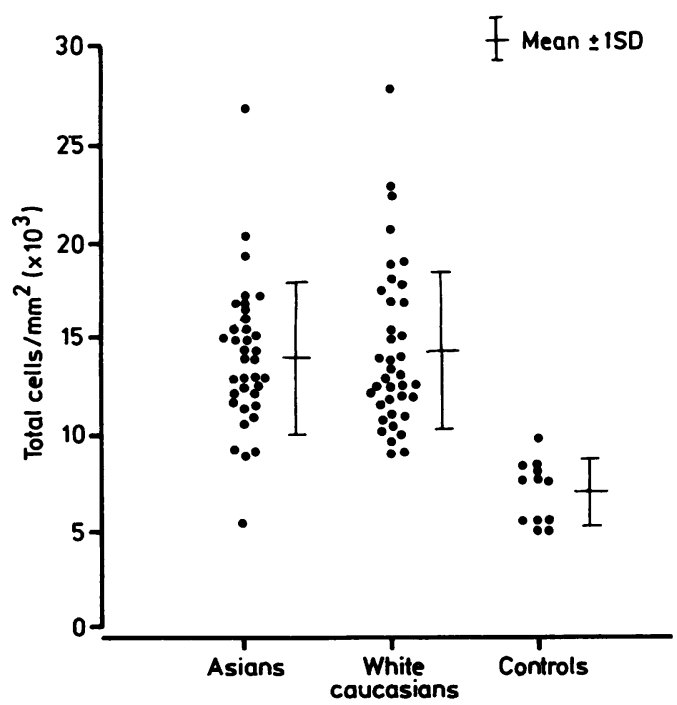

Figure 1 Total cell density in lamina propria of Asians $(n=36)$, Caucasians $(n=38)$, and normal controls $(n=12)$. 


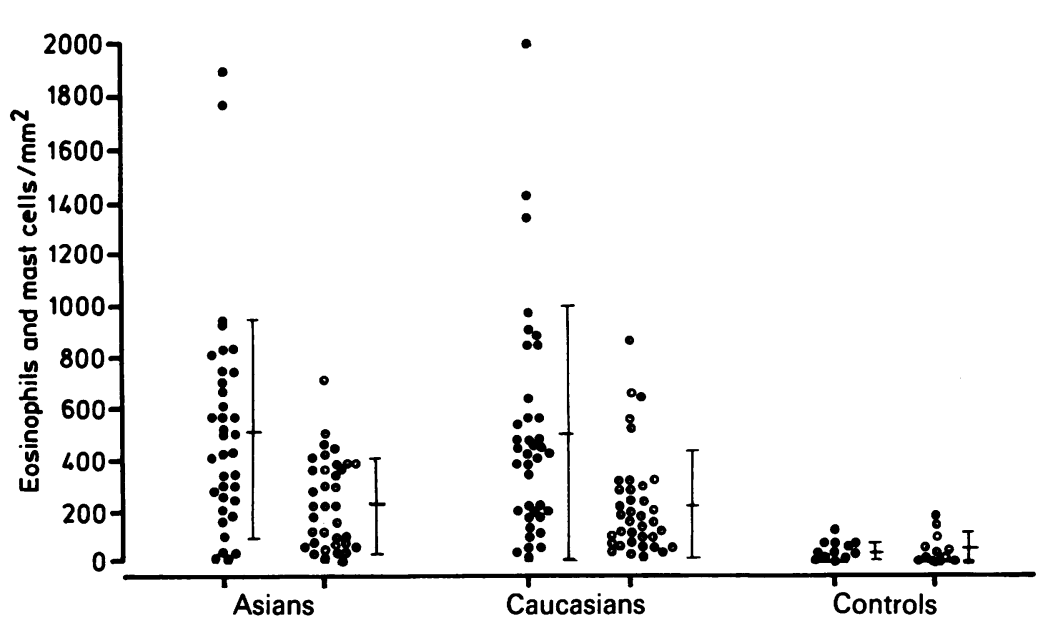

Figure 2 Eosinophil (๑) and mast cell ( $\odot)$ densities in lamina propria of Asians, Caucasians, and control subjects.

summarised in table 3. Eosinophils were increased in most patients in both groups, but mast cell numbers were either raised or normal in a similar proportion of subjects.

The correlation between the various blood, tissue, and serum elements in the patients with ulcerative colitis were examined. In both Asians and Caucasians there was no correlation between circulating and lamina propria eosinophil counts $(r=-0.17$ and $r-0.09$, respectively). Moreover, blood eosinophils did not correlate with other tissue elements or blood indices, except for a highly significant positive association with the leucocyte count in the caucasians (fig 3).

There was a weak correlation between the lamina propria eosinophil and mast cell densities in both groups (Asians: $r=0.36, p<0.05$; Caucasians: $r=0.40, p<0.02)$. In the Asians lamina propria eosinophil densities were negatively correlated with serum orosomucoid concentrations (fig 4); this was not seen in the Caucasians $(r=0.056)$. In both groups mast cell densities were also negatively correlated with the serum orosomucoid concentrations (Asians: $\mathrm{r}=-0.35, \mathrm{p}<0.05$; Caucasians: $\mathrm{r}=-0.49, \mathrm{p}<0.01)$. There was a predictable association between serum orosomucoid concentrations and blood leucocyte counts. In the Asians this was weak $(r=0.32, p<0.05)$ but in the Caucasians it was highly significant $(\mathrm{r}=0.54, \mathrm{p}<0.001)$.

Data were compared between Asians presenting with an eosinophilia $(n=27)$ and those not doing so $(n=30)$. Apart from the mean blood leucocyte count $( \pm 1 \mathrm{SD}) 10 \cdot 1(3 \cdot 1)$ and $8 \cdot 7$ (3.1), respectively, $\mathrm{p}<0 \cdot 05$-there was no difference in any of the indices measured during the study.

Intraobserver variation and the resultant
Table 3 Occurrence of increased lamina propria cell densities in Asians and Caucasians with ulcerative colitis

\begin{tabular}{lcc}
\hline & Asians & Caucasians \\
\hline Increased total cell density & 32 & 35 \\
Normal cell density & 4 & 13 \\
Increased eosinophils & 31 & 32 \\
Normal density & 5 & 6 \\
Increased mast cells & 19 & 16 \\
Normal density & 17 & 22 \\
\hline
\end{tabular}

reproducibility of the cell counts was regarded as satisfactory by the close agreement in figures obtained for the densities of total cells $(r=0.883, p<0.001)$, eosinophils $(r=0.979$, $\mathrm{p}<0.001)$, and mast cells $(\mathrm{r}=0.991, \mathrm{p}<0.001)$.

\section{Discussion}

Studies investigating circulating and tissue eosinophils in ulcerative colitis ${ }^{24}$ have suggested an allergic or IgE mediated mechanism as an explanation for the apparent high incidence of eosinophilia in patients. These studies were either qualitative or semiquantitative, however, and there was poor correlation between blood and tissue numbers. Moreover, patients were receiving maintenance drug treatment with sulphasalazine, and one study used a definition of eosinophilia $\left(0.2 \times 10^{9} / 1\right)$ which would be regarded as too low in today's laboratories. ${ }^{2}$ A pathological study by Bercovitz and Sommers remains the only study to have counted eosinophils in colorectal tissue. ${ }^{8}$

In contrast, mast cell numbers have been extensively investigated because of their role in the release of allergic inflammatory mediators such as histamine and ECF-A under the influence of IgE antibodies. Results have been contradictory, with some authors reporting increased $^{89}$ and normal ${ }^{14}{ }^{15}$ numbers compared with those in healthy colonic tissue. The relevance of mast cells in the initiation and maintenance of the inflammatory response in ulcerative colitis is therefore still undetermined. Eosinophils seem to be more closely involved but their exact role is hypothetical. In our study Asian immigrants with ulcerative colitis who had presented with well documented eosinophilia were investigated to assess the possibility that allergic mechanisms might be present in the absence of other clinical conditions which could explain this feature. At the same time further assessment of any association between other relevant cellular components and inflammatory indices was undertaken.

The various cell densities in both disease groups were much higher than those of the control group. Although the latter was small, the density of mast cells in the lamina propria was comparable with that reported by Lloyd $e t$

Table 2 Details of blood variables (where appropriate) and rectal lamina propria cell densities in Asians, Caucasians, and controls with normal bowel

\begin{tabular}{lcccc}
\hline & Asians & Caucasians & Controls & $p$ Value \\
\hline Rectal cell density $\left(\times 10^{3} / \mathrm{mm}^{2}\right)$ & $13.98(3.76)$ & $14.31(4 \cdot 22)$ & $7 \cdot 05(1.58)$ & $<0.0001$ \\
Eosinophil density $\left(\mathrm{cells} / \mathrm{mm}^{2}\right)$ & $518(417)$ & $497(476)$ & $42(38)$ & $<0.005$ \\
Mast cell density $\left(\right.$ cells $\left./ \mathrm{mm}^{2}\right)$ & $235(170)$ & $218(196)$ & $55(60)$ & $<0.01$ \\
Leucocyte count $\left(\times 10^{9} / 1\right)$ & $8 \cdot 4(2 \cdot 7)$ & $10 \cdot 2(3 \cdot 0)$ & - & $<0.05$ \\
Blood eosinophils $\left(\times 10^{9} / 1\right)$ & $0.56(0.50)$ & $0.23(0 \cdot 33)$ & - & $<0.0005$ \\
Serum orosomucoid $(\mathbf{g} / \mathrm{l})$ & $1.32(0.66)$ & $1.96(0 \cdot 80)$ & - & $<0.001$ \\
\hline
\end{tabular}


Figure 3 Correlation between circulating eosinophils and total leucocyte count in Caucasians.

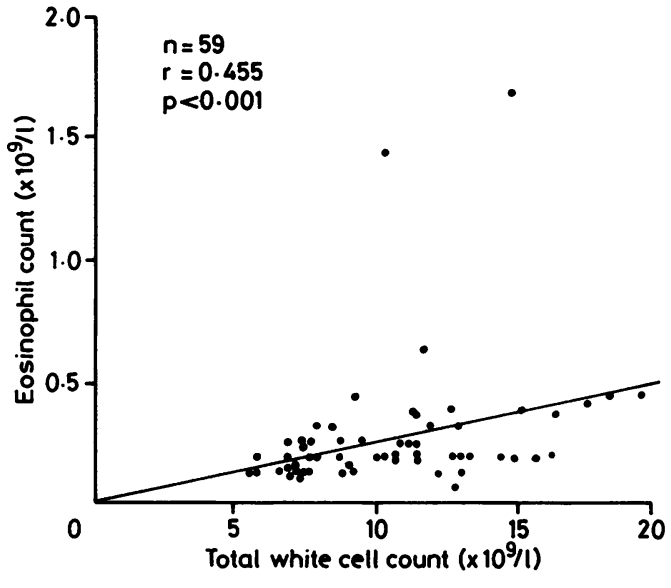

$a l,{ }^{14}$ although higher than that calculated by McAuley and Sommers in 1961 in their quantitative study. ${ }^{8}$ Such mast cell densities suggest that any sampling errors (if present) concerning the degree of representation of disease activity were small and affected both groups equally. Despite raised numbers, however, the presence or absence of such an increase in individual biopsy specimens was randomly distributed in both groups. Furthermore, there was no positive relation between mast cell density and other inflammatory indices such as serum orosomucoid, blood leucocytes, and total inflammatory cell density (except for a weak one with the latter in Asians). These findings would support the contention that mast cell participation in the inflammatory process of ulcerative colitis is non-specific. ${ }^{15}$ Eosinophil density in the lamina propria was increased equally in Asians and Caucasians in accordance with previous experience. Histologically, the inflammatory process seemed to be similar in both ethnic groups.

The various indices and their interrelation were studied in the Asian group. The eosinophil and mast cell infiltrates were weakly correlated, possibly indicating a functional link. These cell densities, however, seemed to be independent of the systemic inflammatory indices and the circulating eosinophil count. Mast cells and eosinophils were negatively correlated with the serum orosomucoid concentration and did not correlate at all with the total leucocyte count. Only mast cells that have not degranulated would be visible following orthodox staining techniques for light micro-
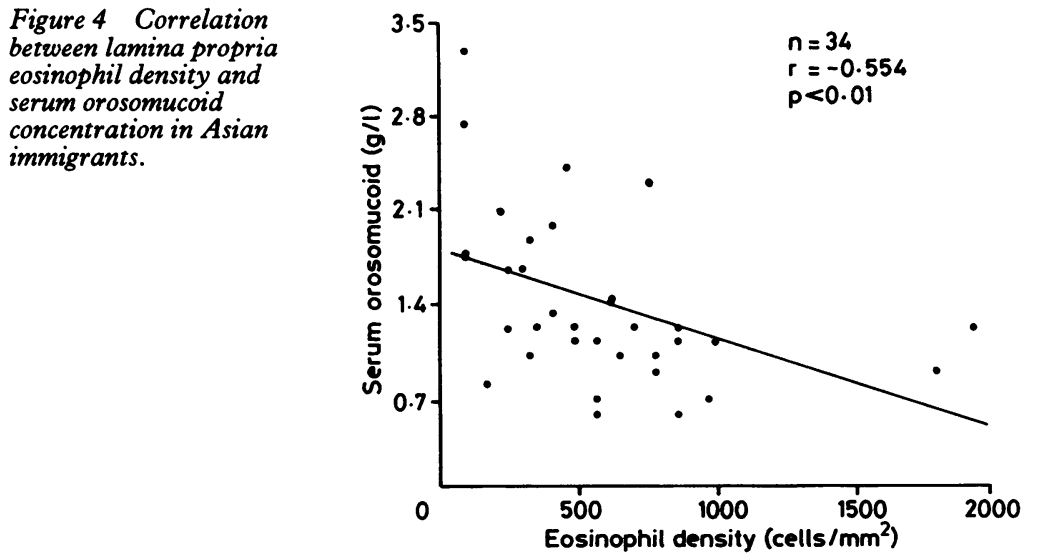

scopy. Electron microscopy, however, has shown clinically important numbers of degranulated cells in affected areas in inflammatory bowel disease $^{16}$ the activity of which is positively correlated with serum orosomucoid concentrations. This would therefore explain the negative correlation of mast cells, but not eosinophils, to orosomucoid concentrations. Nevertheless, mast cell density was correlated, albeit weakly, with eosinophil density, and the association between mast cell degranulation and the inflammatory processes in inflammatory bowel disease remains speculative.

These results suggest that mast cells and particularly eosinophils were influenced or affected by mechanisms other than those usually mirrored by orthodox variables. These might have included an association with IgE secreting plasma cells or histamine release factors not investigated in this study. Alternatively, other local immune reactions may have been involved such as an Arthus type mechanism. ${ }^{17}$ Similarly, raised blood eosinophil numbers do not seem to be influenced by tissue inflammatory activity, indicating that alternative inflammatory mediators or immune mechanisms may have been responsible for their presence. Other classes of immunoglobulins have been shown to participate in the immune response to cow's milk in patients with ulcerative colitis and Crohn's disease, for example. ${ }^{18}$ It is conceivable that Asians may respond to such circumstances to a greater degree than the indigenous population.

In the Caucasian group the histological findings and associations with systemic indices were broadly similar to those in the Asian group in that no consistent pattern emerged to indicate alternative mechanisms to those reflected by the orthodox variables measured. Some important differences, however, were detected. There was a highly significant association between the blood eosinophil and total leucocyte counts and between the latter and the serum orosomucoid-these being absent or weak in the Asian group. Both the leucocyte count and serum orosomucoid concentrations reflect inflammatory activity in ulcerative colitis, and apart from showing a close correlation with each other were significantly higher in this group than in the Asian group. Blood eosinophil counts, nearly all of which were within the currently accepted normal range, seem to have passively reflected such inflammatory activity. This accords with changes in eosinophil numbers monitored by previous authors. ${ }^{219}$ Most of the patients in those studies also had eosinophil counts within the current normal range.

This study did not find any association between numbers of circulating and tissue eosinophils, particularly in the Asian immigrants. Histologically, mast cells did not seem to have a leading role in the inflammatory process, the numbers passively reflecting other indices of active ulcerative colitis. In the Asian group circumstantial evidence has been provided that mechanisms other than those reflected in an orthodox, established manner, in the Caucasians may have a role in the inflammatory process. 
1 Benfield GFA, Asquith P. Eosinophilia and ulcerative colitis-influence of ethnic origin. Postgrad Med J 1986 62:1101-5.

2 Wright R, Truelove SC. Circulating and tissue eosinophils. Am J Dig Dis 1966;11:831-46.

3 Heatley RV, James PD. Eosinophils in the rectal mucosa. Gut 1978;20:787-91.

4 Riis $P$, Anthonisen P.L Eosinophilia in peripheral blood and inflammatory exudate in non-specific proctocolitis. Acto Med Scand 1964;175:85-9.

5 Heatley RV, Calcraft BJ, Fifield R, Rhodes J, Whitehead RH, Newcombe RG. Immunoglobulin $\mathrm{E}$ in rectal mucosa of patients with proctitis. Lancet 1975;ii:1010-12.

6 O'Donoghue DP, Kumar P. Rectal IgE cells in inflammatory bowel disease. Gut 1977;18:A986.

7 Binder V, Hvidberg E. Histamine content of rectal mucosa in ulcerative colitis. Gut 1967;8:24-8.

8 McAuley RL, Sommers SC. Mast cells in nonspecific ulcerative colitis. Am J Dig Dis 1961;6:223-36.

9 Bercovitz ZT, Sommers SC. Altered inflammatory reaction in non-specific ulcerative colitis. Arch Intern Med 1966; in non-specific

$10 \mathrm{Li} \mathrm{CY,} \mathrm{Yam} \mathrm{LT,} \mathrm{Crosby} \mathrm{WH.} \mathrm{Histochemical} \mathrm{characteriza-}$ tion of cellular and structural elements of the human spleen. J Histochem Cytochem 1972;20:1049-58.

11 Blaies DM, Williams JF. A simplified method for staining mast cells with astra blue. Stain Technol 1981;56:91-4.

12 Marner IL, Friborg S, Simonsen E. Disease activity and serum proteins in ulcerative colitis immunochemical quantitation. Scand J Gastroenterol 1975;10:537-44.

13 Jensen KB, Jarnum J, Koudahl G, Kristensen M. Serum orosomucoid in ulcerative colitis. Its relation to clinical activity, protein loss and turnover of albumin and $\mathrm{IgG}$. activity, protein loss and turnover of alb

14 Lloyd G, Green FHY, Fox H, Mani V, Turnberg LA. Mast cells and immunoglobulin $\mathrm{E}$ in inflammatory bowel disease. Gut 1975;16:861-6.

15 Sanderson IR, Leung KPB, Pearce FL, Walker-Smith JA Lamina propria mast cells in biopsies from children with Crohn's disease. J Clin Pathol 1986;39:279-83.

16 Ranlov P, Nielson MH, Wanstrup J. Ultrastructure of the ileum in Crohn's disease: immune lesions and mastocytosis. Scand J Gastroenterol 1972;7:471-6.

17 Jewell DP, Rhodes JM. Immunology of ulcerative colitis. In: Allan RN, Keighly MRB, Alexander-Williams J, Hawkins $\mathrm{C}$, eds. Inflammatory bowel disease. Churchill Hawkins C, eds. Inflammatory bowel

18 Knoflach P, Park BH, Cunningham R, Weiser MM, Albini B. Serum antibodies to cow's milk protein in ulcerative colitis and Crohn's disease. Gastroenterol 1987;92:479-85. 19 Riisager PM. Eosinophil leucocytes in ulcerative colitis Lancet 1959;ii:1008-9. 